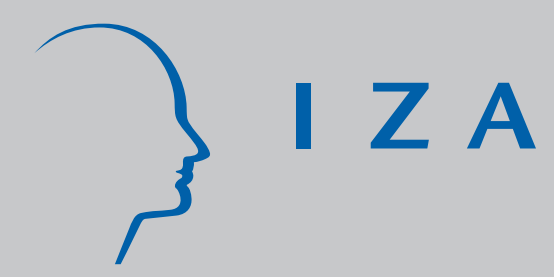

IZA DP No. 915

Macroeconomic Impacts of ALMP on the Matching Process in West Germany

Reinhard Hujer

Christopher Zeiss

October 2003 


\title{
Macroeconomic Impacts of ALMP on the Matching Process in West Germany
}

\author{
Reinhard Hujer \\ University of Frankfurt and IZA Bonn \\ Christopher Zeiss \\ University of Frankfurt \\ Discussion Paper No. 915 \\ October 2003
}

\author{
IZA \\ P.O. Box 7240 \\ D-53072 Bonn \\ Germany \\ Tel.: +49-228-3894-0 \\ Fax: +49-228-3894-210 \\ Email: iza@iza.org
}

This Discussion Paper is issued within the framework of IZA's research area Evaluation of Labor Market Policies and Projects. Any opinions expressed here are those of the author(s) and not those of the institute. Research disseminated by IZA may include views on policy, but the institute itself takes no institutional policy positions.

The Institute for the Study of Labor (IZA) in Bonn is a local and virtual international research center and a place of communication between science, politics and business. IZA is an independent, nonprofit limited liability company (Gesellschaft mit beschränkter Haftung) supported by Deutsche Post World Net. The center is associated with the University of Bonn and offers a stimulating research environment through its research networks, research support, and visitors and doctoral programs. IZA engages in (i) original and internationally competitive research in all fields of labor economics, (ii) development of policy concepts, and (iii) dissemination of research results and concepts to the interested public. The current research program deals with (1) mobility and flexibility of labor, (2) internationalization of labor markets, (3) welfare state and labor market, (4) labor markets in transition countries, (5) the future of labor, (6) evaluation of labor market policies and projects and (7) general labor economics.

IZA Discussion Papers often represent preliminary work and are circulated to encourage discussion. Citation of such a paper should account for its provisional character. A revised version may be available on the IZA website (www.iza.org) or directly from the author. 
IZA Discussion Paper No. 915

October 2003

\begin{abstract}

\section{Macroeconomic Impacts of ALMP on the Matching Process in West Germany}

This paper investigates the macroeconomic effects of job creation schemes and vocational training on the matching processes in West Germany. The empirical analysis is based on regional data for local employment office districts for the period from 1999 to 2003. The empirical model relies on a dynamic version of a matching function augmented by ALMP. In order to obtain consistent estimates in the presence of a dynamic panel data model, a firstdifferences GMM estimator and a transformed maximum likelihood estimator are applied. Furthermore the paper considers the endogeneity problem of the policy measures. The results obtained from our estimates indicate that vocational training does not significantly affect the matching process and that job creation schemes have a negative effect.
\end{abstract}

JEL Classification: $\quad \mathrm{C} 23, \mathrm{E} 24, \mathrm{H} 43, \mathrm{~J} 64, \mathrm{~J} 68$

Keywords: Active Labour Market Policy, dynamic panel data model, matching function, search models

Corresponding author:

Reinhard Hujer

Department of Economics and Business Administration

University of Frankfurt

Mertonstr.17

60054 Frankfurt/M

Germany

Email: hujer@wiwi.uni-frankfurt.de 


\section{Introduction}

The evaluation of active labour market policies (ALMP) gained intensely in importance over the last years in Germany. In the view of the immense spending on ALMP and the persistent and high unemployment rate, the question whether ALMP helps to improve the situation on the labour market has become most important for policy makers. Furthermore, the debateable success of ALMP has additionally enforced the current political discussion whether ALMP is the suitable tool to solve the unemployment problem.

The econometric evaluation of ALMP is mostly done with data on the individual level (see e.g. Heckman, LaLonde, and Smith (1999)). However, a microeconomic approach using individual data usually ignores impacts on non-participants. Therefore the supplementation with a macroeconomic approach using aggregate data is needed to obtain a complete picture of the effects of ALMP. In particular, ALMP is often suspected to have a positive effect on the individual level but a zero or even a negative effect on the whole economy. In this context, deadweight losses, substitution and displacement effects have received substantial attention in the literature (see e.g. Layard, Nickell, and Jackman (1991) or OECD (1993)). In contrast to microeconometric studies, the theoretical foundation of the empirical model for a macroeconometric evaluation is not straightforward. The reason is that most of the theoretical literature on ALMP does not provide a model that is applicable for an empirical analysis, because data limitations and immense differences in the institutional setup of ALMP between countries inhibit a direct application of the available theories. ${ }^{1}$

The following empirical analysis of the macroeconomic effects of ALMP will focus on the matching process which determines the inflows into regular employment. The main question is whether ALMP can improve the matching process, i.e. increase the inflows into employment. Our empirical analysis will rely on the matching function that serves as an approximation of the matching process. ${ }^{2}$ The application of the matching function for the empirical analysis is reasonable since the traditional intention of ALMP is to overcome structural imbalances on the labour market, i.e. to reduce the mismatch in the labour market. Furthermore, the incorporation of ALMP into the matching function is well developed. ${ }^{3}$

The empirical analysis uses regional data for West Germany that allows to estimate the effects of ALMP with a dynamic model. The application of a dynamic model is done in order to account for partial adjustment of the matching process. An additional aspect of this work is the application of adequate estimation methods for dynamic panel data models with fixed effects. Besides the well known GMM estimation methods we will also present the maximum likelihood estimator suggested by Hsiao, Pesaran, and Tahmiscioglu (2002). This maximum likelihood estimator seems to be superior to the GMM estimators for dynamic panel data models with fixed effects.

The existing literature on the macroeconometric analysis of ALMP assumes that ALMP is endogenously determined by a policy reaction function. In this paper we will explicitly consider this problem in order to ensure consistent estimates of the effects of ALMP.

\footnotetext{
${ }^{1}$ A theoretical analysis of the effects of ALMP is given by Calmfors and Lang (1995) and Holmlund and Linden (1993).

${ }^{2}$ See e.g. Petrongolo and Pissarides (2001) for an overview

${ }^{3}$ See for example Lehmann (1995), Bellmann and Jackman (1996), Boeri and Burda (1996), Puhani (1999) and Hagen (2003).
} 
The remainder of this paper is organized as follows. In the next section we will briefly present the institutional setup of ALMP in West Germany. Section 3 derives in detail the matching function augmented by ALMP that is estimated in the empirical analysis. Section 4 discusses the empirical analysis followed by the presentation of the empirical results. Finally, section 6 concludes and gives an outlook for further research.

\section{Active Labour Market Policy in West Germany}

Active labour market policies in Germany are organized by the Federal Employment Office. Since 1998 the legal basis for active labour market policy is the Social Code SGB III ('Sozialgesetzbuch') that has replaced the work support act ('Arbeitsförderungsgesetz', AFG) from 1969.

The Federal Employment Office and the Federal Government spent in 2002 about 12,2 bn Euro on active labour market policies in West Germany. This is about 27,7 percent of the total spending on labour market policies. The most important measures in 2002 have been vocational training ('Förderung der beruflichen Weiterbildung', VT) with 4.04 bn Euro and subsidized employment, consisting primarily of traditional job creation schemes ('Arbeitsbeschaffungsmaßnahmen', JCS) with 0.69 bn Euro. The following analysis will therefore be restricted to job creation schemes and vocational training programmes. Structural Adjustment Schemes ('Strukturanpassungsmaßnahmen') which are only substantial for East Germany are excluded from the analysis.

Vocational Training consists of further training and retraining programmes. The objective of retraining and further training programmes is to adjust the skills of the unemployed to the actual requirements on the labour market. Additionally further training programmes should provide an opportunity to finish a vocational education. The Federal Employment Office pays the costs of the training measures and a subsistence allowance to the participants, which amounts to 60 per cent (67 with one or more children) of the previous net income (equal to unemployment benefit).

Job Creation Schemes are subsidized jobs mostly in non-profit organizations. Major requirement for the subsidization is that the activity is of value to the society and additional in nature, that is without the subsidy they could not be executed. They include limited employment for long-term unemployed in projects to improve their labour market prospects. Even though JCS should be co-financed measures where between $30 \%$ and $75 \%$ of the costs are subsidies by the Federal Employment Office and the rest is paid by the implementing institution (public or private legal entities, mainly municipalities), exceptions can be made in the direction of a higher subsidy-quota (up to 100\%). The subsidy is normally paid for 12 months but can be extended up to 24 and even 36 months if it is followed by regular employment. An important point regarding the further analysis is that a participant in a job creation scheme is registered as an employed person by the Federal Employment Office, i.e. the person is not registered as unemployed.

Considering the development of the expenditures form 1999 up to 2002, we find that the total expenditures for ALMP increase between 1999 and 2002 with 9.6 percent. Vocational training increases with 1.6 percent and JCS decreases with -36.7 percent. The major reason for the decline of JCS can be seen in the budgetary problems of the Federal Employment Office and the Federal Government. Furthermore the JCS activity was reduced since the ability of JCS 
to help the unemployed to get back to regular work is rather questionable. Especially latest empirical evidence on the individual level from Hujer, Caliendo, and Thomsen (2003) suggest that JCS do not have any positive effects on the re-employment probability.

\section{The Augmented Matching Function}

Key element of our empirical analysis will be a matching function augmented by ALMP. The matching function serves as an approximation of the matching process in the labour market, where the matching process is costly and time consuming (Pissarides, 2000). The matching function determines the inflows into regular employment by the stock of unemployed and the stock of vacancies. For the following we are interested in the question whether ALMP can improve the matching process by improving the search effectiveness of the unemployed.

Calmfors (1994) gives three explanations how ALMP can help to improve the search effectiveness. First, ALMP can promote the search intensity of the programme participants by encouraging them to search more actively. Second, ALMP can speed up the matching process by upgrading the skills of the participants and by adjusting the skills to the structure of the labour demand. The latter confirms the traditional intention of ALMP to overcome structural imbalances on the labour market by adjusting the structure of the labour supply to demand (Calmfors and Skedinger, 1995). Third, a programme participation can serve as a substitute for regular work experience which can reduce the employer's uncertainty about the employability of the job applicant (Calmfors, 1994).

Considering standard search theory, an improved search effectiveness of the unemployed does have several effects on the labour market. First, for a given stock of unemployed and vacancies the number of matches increases. Assuming a constant quit rate (i.e. the rate at which employed workers are laid-off), unemployment decreases and employment increases. Following Calmfors (1994), this results in a shift of the Beveridge-Curve to the origin, i.e. for a given number of vacancies there is less unemployment. Therefore ALMP can lower unemployment if the source of a high unemployment rate are structural imbalances in the labour market. Note that in a situation where high labour costs are responsible for a high unemployment rate an improved matching process can have only marginal effects. This point is extremely important for Germany, since high labour costs seem to be the major reason for the high unemployment rate.

Additionally, there are also effects on the firm's employment decision and the wage setting process. An improved matching process shortens the time a vacancy remains open. Since this reduces the costs of maintaining a vacancy, firms will declare more vacancies which is equivalent to an increase of the labour demand. On the one hand, the higher labour demand rises the probability for the workers to get a suitable job offer. This enhances the position of the workers in a wage bargaining process and therefore leads to an upward pressure on the wages. On the other hand, the shorter time a vacancy remains open leads to a better bargaining position for the firm, since laid-off workers can be replaced quicker. This enables the firm to negotiate lower wages at each level of employment (Calmfors, Forslund, and Hemström, 2002). Therefore the rise of the labour demand, due to the improved matching process, results in higher employment whereas the effect on the wages is ambiguous.

ALMP programmes are also expected to have negative effects on the matching process. Espe- 
cially locking-in effects seem to be of major importance. If an ALMP programme is associated with full time employment like most JCS programmes, the time remaining for an active job search is reduced (Holmlund and Linden, 1993). Therefore it is reasonable to expect a lower search effectiveness for the participants currently being placed in a programme compared to the participants after programme participation. Furthermore, in this case a positive effect of ALMP can only result from a positive after-programme effect that compensates a negative locking-in effect.

Besides the effects on the matching process there are several other channels how ALMP can affect the labour market. For example effects on the productivity, the labour supply, the competition in the labour market and reduced welfare losses of unemployment. The analysis of the matching process is therefore a partial-analytic approach which concentrates only on one aspect of the effects of ALMP. As the following empirical analysis investigates only the effects on the matching process we omit a discussion of alternative channels. A comprehensive presentation of the different effects of ALMP can be found in Calmfors (1994) and Calmfors, Forslund, and Hemström (2002).

In order to analyse the effects of ALMP on the matching process we will derive a matching function augmented by ALMP as suggested by Lehmann (1995) and Puhani (1999). Using a usual Cobb-Douglas specification we can write the augmented matching function as:

$$
h=A v^{\beta_{v}}(c u)^{\beta_{u}}
$$

where $h$ are the outflows from unemployment into regular employment relative to the labour force, $v$ are the vacancies relative to the labour force, $u$ are the unemployed relative to the labour force, $A$ is a scale parameter and $c$ is a search effectiveness index. The scale parameter $A$ is interpreted as a mismatch parameter that captures several determinants of the matching process. Amongst others these determinants can be the differences in geographic and skill characteristics as well as the preferences and the institutional set incentives which influences the search behaviour (Puhani, 1999). cu defines the search effective stock of the unemployed, where $c$ is affected by AMLP. The basic idea is that ALMP helps to rise the number of unemployed who search effectively for a job. In order to introduce ALMP into the matching function we define the parameter $c$ as:

$$
c=\mu(1+\theta) \text { with } \theta=\sum_{j=1}^{J} \tau_{j} p_{j}
$$

The parameter $\mu$ denotes the search effectiveness of the unemployed in the absence of ALMP and $\theta$ is the impact of the ALMP programmes on the search effectiveness. The general effect $\theta$ can be decomposed into the several effects $\tau_{i}$ of the different ALMP measures $p_{j}$. The ALMP measure $p_{j}$ can either be defined as the number of participants in ALMP programmes, or can be defined as the expenditures on ALMP. In our empirical analysis we will use the number of participants in JCS and VT relative to the labour force. The marginal effect of the policy measure on the search effectiveness is given by: $\frac{\partial c}{\partial p_{i}}=\mu \tau_{i}$.

The log-linearized form of equation (1) 


$$
\ln h=\ln A+\beta_{v} \ln v+\beta_{u} \ln u+\beta_{u} \ln (\mu(1+\theta))
$$

can be approximated for small $\theta$ as:

$$
\ln h=A^{*}+\beta_{v} \ln v+\beta_{u} \ln u+\beta_{u} \sum_{j=1}^{J} \tau_{j} p_{j}
$$

where $A^{*}=\ln A+\beta_{u} \ln \mu$.

In our analysis we do not only differentiate between JCS and VT but also include the programme measures with several lags. The reason is that we want to account for the locking-in effect of ALMP. Unfortunately, our aggregate data does not allow a differentiation between participants currently being placed in a programme and participants after programme participation. Therefore, we include several lags of the ALMP measures in order to obtain the net effect, i.e. the effect that incorporates the locking-in effect and the after programme effect.

\section{Empirical Analysis}

For the empirical analysis of the effects of JCS and VT we use data for 141 regions in West Germany. The regional units are defined by the administrative areas of the local offices of the Federal Employment Office. The time range reaches from the first quarter in 1999 to the first quarter in 2003, i.e. for each region we face a time series of 17 quarters. The descriptive statistics for the data can be found in Table 1.

Table 1: Descriptive Statistics

\begin{tabular}{l|rrrr}
\hline \hline Variable & Min & Max & Mean & Std. \\
\hline \hline Number of labour office districts: 141 & & & & \\
Number of observations: 2397 & & & & \\
Time Range: 1999:1 - 2003:1 (Quarterly Data) & & & & \\
\hline \hline Inflows from Unemployment into Employment & 909 & 15578 & 3430 & 1884 \\
Participants in JCS & 2 & 2181 & 313 & 315 \\
Participants in VT & 135 & 8500 & 1395 & 906 \\
Unemployment & 3318 & 88317 & 17443 & 11424 \\
Vacancies & 383 & 29755 & 2849 & 2547 \\
Labour Force & 58974 & 1007761 & 202401 & 121036 \\
\hline \hline
\end{tabular}

The augmented matching function we seek to estimate is given by:

$$
\ln h_{i t}=A_{i t}^{*}+\beta_{v} \ln v_{i t-1}+\beta_{u} \ln u_{i t-1}+\phi(L) J C S_{i t}+\varphi(L) V T_{i t},
$$

where $h_{i t}$ are the outflows from unemployment into employment relative to the labour force, $v_{i t}$ and $u_{i t}$ are the vacancy and the unemployment rate relative to the labour force, $J C S_{i t}$ and $V T_{i t}$ are the policy measures for both ALMP programmes and $i$ and $t$ are the indices for the region and the time. $\phi(L)=\phi_{1} L+\phi_{2} L^{2}+\phi_{3} L^{3}+\phi_{4} L^{4}$ and $\varphi(L)=\varphi_{1} L+\varphi_{2} L^{2}+\varphi_{3} L^{3}+\varphi_{4} L^{4}$ are associated polynomials in the lag operator. The variable $A_{i t}^{*}$ captures the remaining explanatory variables for $h_{i t}$ 


$$
A_{i t}=A+\gamma \ln h_{i t-1}+Z_{t}+\mu_{i}+\delta t+e_{i t},
$$

where $A$ is a constant, $Z_{t}$ is a vector of seasonal dummies, $\mu_{i}$ is a fixed effect (the regional unobserved heterogeneity), $t$ is a time trend and $e_{i t}$ is a residual varying over $t$ and $i$. Furthermore, we use a dynamic specification in order to account for partial adjustment in the matching process.

The empirical model combines stock and flow data where monthly data is aggregated to quarterly data. The flow data, i.e. the outflows from unemployment into employment in $t$ result from the sum of the outflows over the three months of the associated quarter. The stock data that is used to calculate the unemployment and the vacancy rate results from the last month of the associated quarter, i.e. the stock refers to the end of the quarter.

If $h_{i t}$ is measured as a flow over a time period, and $u_{i t}$ and $v_{i t}$ as stocks at some point during the period, $u_{i t}$ and $v_{i t}$ are depleted by $h_{i t}$ and thus are endogenously determined with respect to $h_{i t}$ (Petrongolo and Pissarides, 2001). In particular it is reasonable to assume that $E\left(e_{i t} u_{i s}\right) \neq 0$ and $E\left(e_{i t} v_{i s}\right) \neq 0$ for $s \geq t$ and zero otherwise. That is the $u_{i t}$ and $v_{i t}$ are independently distributed conditionally only on future values of $e_{i t}$. In order to avoid the simultaneity problem we include the unemployment and the vacancy rate with one lag. This is also reasonable, since the lagged unemployment and vacancy rate refers to the stock that is available at the beginning of the period. The lagged unemployment and vacancy rate can be treated as a weak exogenous variable, as weak exogeneity requires that only future values of the regressor are correlated with the residual. That is the residual $e_{i t}$ is independently distributed conditional on current and lagged values of $u_{i t-1}$ and $v_{i t-1}$ but not of their future values.

As ALMP measure we use the participants in JCS and VT relative to the labour force. In order to account for the fact that participants in JCS are registered as employed, we added them to the stock of unemployed and subtracted the inflows into JCS from the outflows from unemployment into employment.

The stock of participants that is used to calculate the participation rate, refers also to the end of the quarter. Therefore the participation rates are included at least with one lag, since the lagged participation rate denotes the participation rate at the beginning of the period $t$. Furthermore both ALMP measures are included up to the fourth lag, which is reasoned by a mean duration of the programmes between 8 and 12 months.

The setup of the model and the data also avoids the simultaneity problem of ALMP which is a major issue in the estimation of the effects of ALMP. Generally, ALMP is assumed to be determined by a policy reaction function where the inflows into employment could be one argument besides others (Calmfors and Skedinger, 1995). ${ }^{4}$ Most empirical studies of the macroeconomic effects of ALMP use instrumental variable estimators in order to account for the endogeneity problem. ${ }^{5}$ The major problem of this approach is that an adequate set of instruments is apriori unknown or not available due to data limitations. That is, the available instruments have hardly any predictive power for the ALMP measures or are correlated with the residual term of the regression equation. For our empirical analysis we can avoid such questionable instrumentation

\footnotetext{
${ }^{4}$ See Blien (2002) for an extensive discussion of the allocation process for the funds spent on ALMP.

${ }^{5}$ See for example Calmfors and Skedinger (1995), Boeri and Burda (1996) and Hagen (2003).
} 
strategies since it is reasonable to assume that the participants in ALMP at the beginning of the period are not determined by the matches of the same period. In particular, we assume for the ALMP measures a similar correlation structure as for the unemployment and the vacancy rate. That is we assume that $E\left(e_{i t} J C S_{i s}\right) \neq 0 E\left(e_{i t} V T_{i s}\right) \neq 0$ for $s \geq t$ and zero otherwise. Thus we can treat the lagged policy measures as weak exogenous variables.

The estimation of the model (3) with the least squares dummy variable (LSDV) estimator for finite $T$ is inconsistent due to the incidental parameter problem. Only for $T$ tending to infinite the LSDV is consistent. In order to get around the incidental parameter problem one may write the model in first differences where the fixed effects are removed:

$\Delta \ln h_{i t}=\delta+\gamma \Delta \ln h_{i t-1}+\beta_{v} \Delta \ln v_{i t-1}+\beta_{u} \Delta \ln u_{i t-1}+\phi(L) \Delta J C S_{i t}+\varphi(L) \Delta V T_{i t}+\Delta Z_{t}+\Delta e_{i t}$

In this equation we face the problem that $E\left(\Delta \ln h_{i t-1} \Delta e_{i t}\right) \neq 0, E\left(\Delta J C S_{i t-1} \Delta e_{i t}\right) \neq 0$, $E\left(\Delta V T_{i t-1} \Delta e_{i t}\right) \neq 0, E\left(\Delta u_{i t-1} \Delta e_{i t}\right) \neq 0$ and $E\left(\Delta v_{i t-1} \Delta e_{i t}\right) \neq 0$. The first-differences GMM estimator proposed by Arellano and Bond (1991) suggests to use lagged levels as instruments for the lagged dependent and the explanatory variables. In particular the available moment conditions are:

$$
\begin{aligned}
E\left(\Delta e_{i t} \ln h_{i t-g}\right) & \text { for } g=2,3 \cdots, t-1 \\
E\left(\Delta e_{i t} J C S_{i t-1-g}\right) & \text { for } g=1,2 \cdots, t-2 \\
E\left(\Delta e_{i t} J C S_{i t-1-g}\right) & \text { for } g=1,2 \cdots, t-2 \\
E\left(\Delta e_{i t} \ln u_{i t-1-g}\right) & \text { for } g=1,2 \cdots, t-2 \\
E\left(\Delta e_{i t} \ln v_{i t-1-g}\right) & \text { for } g=1,2 \cdots, t-2
\end{aligned}
$$

The time trend and the seasonal dummies are strictly exogenous variables and are simply instrumented by themselves.

Unfortunately, using all available moment conditions leads to a huge number of overidentifying restrictions. This is because the above moment conditions use the complete history of the variables as instruments. The application of too many moment conditions may lead to an overfitting bias (Bond, 2002). Furthermore, the calculation of the associated two-step estimates can become problematic if the number of regional units is below the number of instruments. In order to reduce the number of moment conditions we have excluded all instruments before $t-4$.

As discussed by Blundell, Bond, and Windmeijer (2000), the first-differences GMM estimator proposed by Arellano and Bond (1991) tends to be biased if the autoregressive parameter is near unity. ${ }^{6}$ However, as our dependent variable results from flow data, large autoregressive coefficients near unity are very unlikely. But the application of the first-differences GMM estimator becomes problematic in the case where the variance of the regional effects is too large relative to the variance of $e_{i t}$. The reason is that the utilization of variables in levels as instruments for variables in first differences is rather problematic in this case. If the variables in levels are for a major part driven by the regional effect, the predictive power for variables in first differences is

\footnotetext{
${ }^{6}$ In the extreme case of a unit root process, the first-differences GMM estimator breaks down completely.
} 
very poor. Ahn and Schmidt (1995), and Blundell and Bond (1998) have proposed additional moment conditions to overcome this problem. Unfortunately those moment conditions require the identification of the coefficients for the fixed effects and therefore do not solve the incidental parameter problem. ${ }^{7}$

For the estimation of linear dynamic panel data models with fixed effects Hsiao, Pesaran, and Tahmiscioglu (2002) have suggested a transformed maximum likelihood estimator (MLE). This estimator is more efficient than the first-differences GMM estimator and does perform well in the case of near unit roots. ${ }^{8}$ Furthermore it also performs better in the case where the variance of the regional effects is large relative to the variance of $e_{i t}$. A detailed presentation of the MLE can be found in the Appendix. One major advantage of the MLE is that we can account explicitly for the weak exogeneity of the lagged explanatory variables without using a huge number of overidentifying restrictions, as it is the case for the first-difference GMM estimator. Additional to the first-differences GMM estimator and the MLE we also will present the results from the LSDV estimator in order to assess the robustness of our results.

\section{Results}

Table 2 contains the estimation results for the MLE, the first-differences GMM (GMM-DIF) estimator and the LSDV estimator. Furthermore, Table 2 also presents the results from an LSDV estimator for a static model where the lagged dependent is excluded. We also present the results from a Wald test of joint significance, a Wald test for constant returns of scale of the augmented matching function, a Sargan test of overidentifying restrictions and a test for first and second order serial correlation. ${ }^{9}$ The absence of second order serial correlation is crucial for the orthogonality conditions of the GMM DIF to be valid. Since the test for second order serial correlation does not allow a rejection of the null hypothesis, the results from the GMM estimators should be handled with care. The set of instruments for the GMM DIF cannot be rejected by the Sargan test. But, due to the relatively large time dimension and the weak exogeneity assumption of the lagged explanatory variables, the number of instruments used for the GMM estimators is very large and exceeds the number of regions although the history is restricted. The presented results for the GMM estimator are the associated two-step estimates. Monte Carlo simulations have shown that the standard errors of the two-step estimates are downward biased. ${ }^{10}$ This is because the standard expression for the asymptotic variance ignores the presence of the estimated parameters in the weight matrix (Bond and Windmeijer, 2002). In order to overcome this problem we apply the finite sample correction proposed by Windmeijer (2000). Monte Carlo results have shown that the corrected variance of the two-step estimator often provides more reliable inference with size proportions similar to those of the one-step variance (Bond and Windmeijer, 2002).

For the MLE we present the additional estimates for the projection parameters $\lambda$, and the variance ratio $\omega=\sigma_{\xi}^{2} / \sigma_{u}^{2}$, both defined in the Appendix. In contrast to the GMM estimator, the calculation of the MLE seems not to suffer from the relatively large time dimension. We

\footnotetext{
${ }^{7}$ Note that all these estimators were developed for the random effects model.

${ }^{8}$ See the Monte-Carlo results from Hsiao, Pesaran, and Tahmiscioglu (2002).

${ }^{9}$ The test for first and second order serial correlation was suggested by Arellano and Bond (1991) and is asymptotically normal distributed.

${ }^{10}$ See for example Arellano and Bond (1991).
} 
used the estimates from the minimum distance estimator (MDE) suggested by Hsiao, Pesaran, and Tahmiscioglu (2002) as starting values for the Newton-Raphson algorithm to compute the MLE. ${ }^{11}$

Considering the estimates for the autoregressive parameter of the dynamic model, we find throughout a small but significant negative estimate. Comparing the different estimators we find for the MLE the highest estimate and for the GMM-DIF estimator the lowest estimate. Since the LSDV estimate for the autoregressive parameter is downward biased, the results from the MLE seem to be more reliable compared to the results from the GMM-DIF and LSDV estimator. Furthermore the LSDV estimator seems to be superior to the GMM-DIF estimator in our case. A major problem for the GMM-DIF estimator seems to be the relatively large time dimension and the presence of second order serial correlation. With respect to the LSDV estimator it should be borne in mind that the relatively large time dimension weakens the problems of the LSDV estimator in the case of a dynamic model. This might be one reason for the rather similar results of the LSDV estimator and MLE.

An important question that arises is whether a negative coefficient for the lagged dependent variable is reasonable. One argument might be that a period of high matching activity is followed by a period with a lower matching activity because the labour market has cleared. On the other hand, a comparison of the results from the static model shows only moderate differences between the estimates from the static and the dynamic model. Therefore, the application of a dynamic model seems not to be crucial for the results. However, as a Wald test for $\gamma=0$ does not reject the null hypothesis for all estimators, we take the dynamic model as the appropriate specification. $^{12}$

Generally we can state that the MLE seems to produce the most reliable results compared to the LSDV and the GMM-DIF estimator. Considering the Wald test of joint significance we find the largest statistic for the MLE, which might be seen as an evidence for a more efficient estimate.

Turning to the parameters for the unemployment and vacancies rate, we find, as expected, a positive and significant parameter for both variables. A Wald test for the restriction $\beta_{u}+\beta_{v}=1$ rejects the hypothesis that the augmented matching function exhibits constant returns of scale. It is noteworthy that the coefficient for the vacancy rate is relatively small compared to the coefficient for the unemployment rate. The reason might be that our data includes only those vacancies that are registered by the employment offices. ${ }^{13}$ Therefore, the vacancy rate in our data set is systematically underestimated and should only be interpreted as an approximation of the real vacancy rate.

For all estimators we find a negative trend and highly significant seasonal dummies. The negative trend is confirmed by the latest rise of the unemployment rate in West Germany.

Considering the coefficients for the ALMP measures we will use the cumulated lag coefficients and the long run multiplier for the interpretation (see also Hujer, Blien, Caliendo, and Zeiss (2002)). Table 3 shows the cumulated lag coefficients and the long run multipliers for JCS and VT for the MLE, the GMM-DIF and the LSDV estimator.

For JCS we find for all estimators a negative and significant impact at $t+1$ that holds up to

\footnotetext{
${ }^{11}$ A description of the MDE can be found in the Appendix.

${ }^{12}$ Results from a Wald test for the restriction $\gamma=0$ : MLE 7.31, GMM-DIF 42.45 and LSDV 35.03.

${ }^{13}$ This problem is extensively discussed by Franz and Smolny (1994).
} 


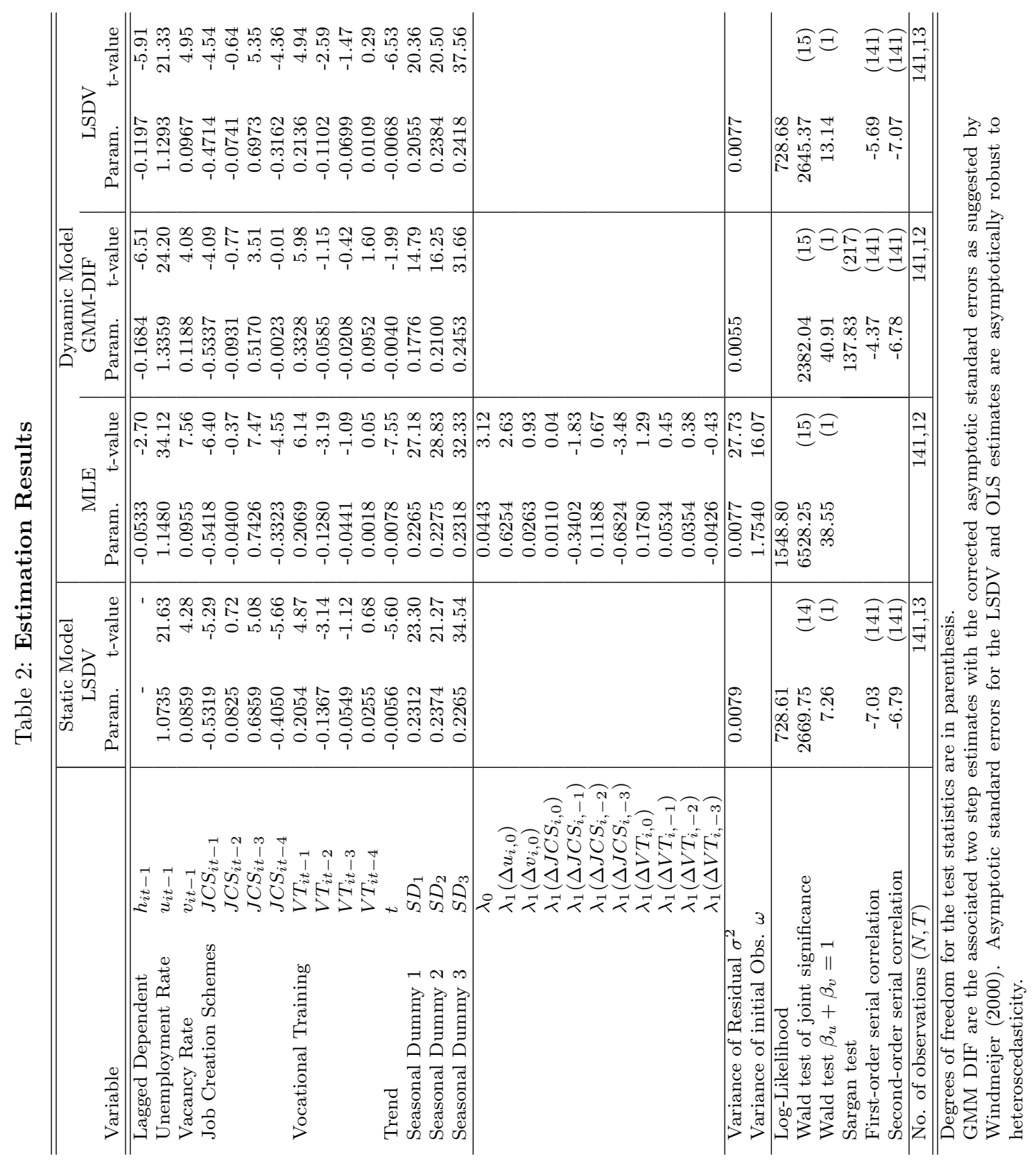


Table 3: Cumulated Lag Coefficients for the effects of ALMP

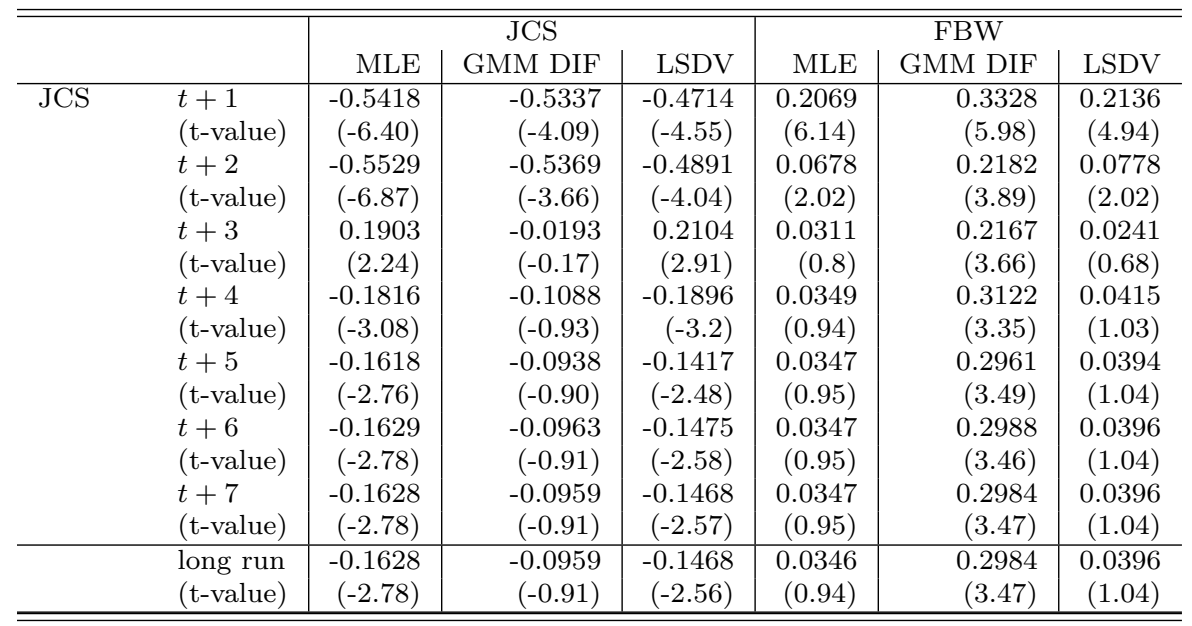

$t+2$. At $t+3$ we find a positive effect and finally at $t+4$ a negative effect that remains for future periods. The long run multiplier is negative significant, i.e. JCS does reduce the number of new matches. This means that JCS is not only an ineffective tool to improve search effectiveness of the unemployed but also worsens the situation. This result confirms to latest microeconometric evidence from Hujer, Caliendo, and Thomsen (2003), where a negative effect of JCS on the individual level was found for West Germany. The positive effect at $t+3$ interestingly coincides with the mean duration of an JCS programme. If an unemployed enters a JCS programme he or she leaves the programme on average after 12 Months, i.e. at $t+3 \cdot{ }^{14}$ This can be seen as an evidence for the presence of a locking-in effect of JCS. Comparing the results from the different estimators we find similar results for the static model and for the MLE and the LSDV estimator. Only for the GMM-DIF estimator we find an insignificant negative effect.

For VT we do find for all estimators a positive significant impact at $t+1$. Whereas this effect vanishes very rapidly for the MLE and the LSDV estimator, it remains positive significant only for the GMM-DIF estimator. The results from the static model are again rather similar to the results from the MLE and LSDV estimator. The long run multiplier is only for the GMM-DIF estimator positive significant and positive insignificant for the remaining estimators. Therefore we can conclude that VT is not able to rise the search effectiveness of the unemployed. In contrast to JCS we do not find an evidence for a deterioration of the labour market situation due to the presence of VT. Furthermore, we cannot find a pattern that could be associated with a locking-in effect of VT.

\section{Conclusion}

We were interested in estimating the effects of ALMP on the matching process in West Germany. Aggregate data for 141 West German local employment office districts for the time span from 1999 to 2003 was used to estimate the effects of job creation schemes and vocational training on the matching process. The empirical analysis was based on a dynamic version of the augmented

\footnotetext{
${ }^{14}$ See Hujer, Caliendo, and Thomsen (2003), Table A.3.
} 
matching function. In order to obtain reliable estimates from the dynamic panel data model we applied the GMM estimator proposed by Arellano and Bond (1991) and the maximum likelihood estimator suggested by Hsiao, Pesaran, and Tahmiscioglu (2002).

The results with respect to job creation schemes are negative and significant. Therefore, we find that job creation schemes reduce the search effectiveness of the unemployed, i.e. reduce the inflows from unemployment into employment. For vocational training we obtain positive but insignificant results. Thus, vocational training seems to be ineffective to improve the search effectiveness of the unemployed.

The ineffectiveness of vocational training to rise the number of new matches may be explained with the latest development of the labour market situation in West Germany. The high unemployment rate in Germany that obviously results from a shortage of the labour demand, leads to a situation where vocational training can hardly improve the labour market situation. This is because vocational training is intended to affect the structure of the labour supply and thus cannot solve the problems on the labour demand side.

For the results concerning job creation schemes it should be emphasized that the negative effect of job creation schemes cannot only be justified by the actual labour market situation. The major reason of the negative effects of job creation seem to be problems that are associated with the institutional setup of the programmes. For example the requirement that the created job is additional may reduce the employability of the participants with respect to a regular job, since the there are too large differences in the skill characteristics between a created and a regular job. Furthermore, the relatively long duration of the programmes seems to be problematic in the presence of locking-in effects.

A major criticism concerning macroeconometric evaluations is that effects of ALMP may be too small to detect them in the noise of aggregation. However, due to the large scale programmes in Germany, effects of ALMP on the whole economy are likely and should therefore be investigated. From our point of view, especially macroeconometric evaluations that consider the ALMP effect on the whole labour market situation are needed. Here we think of general equilibrium models that are applicable for an empirical analysis and allow not only to assess the total effect but also the different channels of the effect of ALMP.

Finally, it should be noted that a complete evaluation process requires both, a micreconometric evaluation and a microeconometric evaluation. Ideally, a microeconometric and a macroeconometric evaluation should be based on the same data source in order to ensure comparable results. 


\section{A Appendix}

\section{A.1 The fixed effects MLE and MDE for $\mathrm{K}$ weak exogenous regressors}

The following section gives a detailed description of the maximum likelihood estimator (MLE) suggested by Hsiao, Pesaran, and Tahmiscioglu (2002). Furthermore, we will extend the notation of Hsiao, Pesaran, and Tahmiscioglu (2002) in order to consider a dynamic panel data model with fixed effects containing $K$ weak exogenous (or predetermined) regressors. ${ }^{15}$ Consider the following linear dynamic panel data model:

$$
y_{i t}=a_{i}+\gamma y_{i t-1}+X_{i t} \beta+u_{i t}
$$

$y_{i t}$ is the dependent variable, $X_{i t}$ is a $(1 \times K)$ vector of weak exogenous regressors and $a_{i}$ is the individual specific fixed effect. Weak exogenous means that $E\left(X_{i t} u_{i s}\right) \neq 0$ for $s<t$, i.e. the residual $u_{i t}$ is independently distributed of current and lagged values of $X_{i t}$ but not of their future values. Furthermore, we assume that the initial values $y_{i 0}$ and $X_{i 0}$ are observable. To remove the fixed effect $a_{i}$ we consider the model in first differences.

$$
\Delta y_{i t}=\gamma \Delta y_{i t-1}+\Delta X_{i t} \beta+\Delta u_{i t}
$$

In order to find the likelihood we define $\Delta W_{i t}=\left(\Delta y_{i t}, \Delta X_{i t}\right)$ and $\Delta \Psi_{i t}=$ $\left(\Delta W_{i t}, \Delta W_{i t-1}, \cdots, \Delta W_{i 1}\right)$ where $\Delta \Psi_{i 0}$ is normalized to unity (Hsiao, Pesaran, and Tahmiscioglu, 2002). Therefore $\Delta \Psi_{i t}$ contains the whole history of $\Delta W_{i t}$ up to the point $t$. The joint density for $\Delta W_{i t}$ conditional on this history is given by:

$$
f\left(\Delta W_{i T} \mid \Psi_{i T-1}\right) f\left(\Delta W_{i T-1} \mid \Delta \Psi_{i T-2}\right) \cdots f\left(\Delta W_{i 2} \mid \Delta \Psi_{i 1}\right) f\left(\Delta W_{i 1}\right)
$$

Since

$$
f\left(\Delta W_{i t} \mid \Psi_{i t-1}\right)=f\left(\Delta y_{i t} \mid X_{i t}, \Psi_{i t-1}\right) f\left(\Delta X_{i t} \mid, \Psi_{i t-1}\right),
$$

the relevant part of the likelihood is simply given by:

$$
\prod_{i=1}^{N} \prod_{t=1}^{T} f\left(\Delta y_{i t} \mid \Delta X_{i t}, \Psi_{i t-1}\right)
$$

For $t=2, \cdots, T$ the density for $\Delta y_{i t}$ is fully specified by (A.2). The problem that remains is to find the density for the initial observation, $f\left(\Delta y_{i 1} \mid \Delta X_{i 1}\right)$, that does not depend on incidental parameters.

Backward substitution gives an expression for $\Delta y_{i 1}$ (assuming the process has started in $-m$ ):

$$
\Delta y_{i 1}=\gamma^{m} \Delta y_{i,-m+1}+\sum_{j=0}^{m-1} \gamma^{j} \Delta X_{i, 1-j} \beta+\sum_{j=0}^{m-1} \gamma^{j} \Delta u_{i, 1-j}
$$

Taking expectations conditional on $\Delta y_{i,-m+1}$ and $\Delta X_{i, 1}, \Delta X_{i, 0}, \cdots, X_{i,-m}$ we get:

$$
E\left[\Delta y_{i 1} \mid \Delta y_{i,-m+1}, \Delta X_{i, 1}, \Delta X_{i, 0}, \cdots, X_{i,-m}\right]=\gamma^{m} \Delta y_{i,-m+1}+\sum_{j=0}^{m-1} \gamma^{j} \Delta X_{i, 1-j} \beta
$$

\footnotetext{
${ }^{15}$ The case of one strict exogenous regressor is presented by Hsiao, Pesaran, and Tahmiscioglu (2002).
} 
Since $\Delta X_{i, 1-j}$ for $j=1,2, \cdots, m$ is not available, $E\left[\Delta y_{i 1} \mid \Delta y_{i,-m+1}, \Delta X_{i, 1}, \Delta X_{i, 0}, \cdots, X_{i,-m}\right]$ is unknown. Treating this expected value as a free parameter to be estimated will again result in an incidental parameter problem. In order to specify the expected value as a function of finite parameters, Hsiao, Pesaran, and Tahmiscioglu (2002) suggest to write them as a function of the observable regressors. In what follows Hsiao, Pesaran, and Tahmiscioglu (2002) assume either:

Assumption i: $|\gamma|<1$ and $m \rightarrow \infty$, i.e. the process has started a long time ago. Then $E\left(\Delta y_{i,-m+1} \mid \Delta X_{i 1}\right)=0$, or

Assumption ii: $m$ is finite, that is the process has started quite recently and the expected value $E\left(\Delta y_{i,-m+1} \mid \Delta X_{i 1}\right)$ is the same across $i$.

Note that Assumption ii only requires that the expected changes in the initial endowments are the same across $i$, and does not require that $|\gamma|<1$ (Hsiao, Pesaran, and Tahmiscioglu, 2002).

The expected value of $\Delta y_{i 1}$ conditional on the $\Delta X_{i 1}$ is given by:

$$
E\left(\Delta y_{i 1} \mid \Delta X_{i 1}\right)=b^{*}+E\left[\sum_{j=0}^{m-1} \gamma^{j} \Delta X_{i, 1-j} \beta \mid \Delta X_{i 1}\right]+E\left[\sum_{j=0}^{m-1} \gamma^{j} \Delta u_{i, 1-j} \mid \Delta X_{i 1}\right]
$$

where $b^{*}=0$ under $\mathbf{i}$ and $b^{*}=b$ under ii. Since we assume that $X_{i t}$ is weak exogenous we can only use $\Delta X_{i 1}$ as regressors for the conditional expected value for $\Delta y_{i 1}$.

Hsiao, Pesaran, and Tahmiscioglu (2002) suggested a projection technique in order to get a computable expression for expected values in equation (A.5). The elements of the sum of first expected value in equation (A.5) can be projected with:

$$
E\left(\Delta X_{i 1-j} \mid \Delta X_{i 1}\right)=g_{j}+\Delta X_{i 1} \Psi_{j}
$$

where $\Psi_{j}$ is a $(K \times K)$ matrix and $g_{j}$ is a $(1 \times K)$ vector. In our case $\Psi_{j}$ and $g_{j}$ depend not only on the autocovariances of the processes determining $X_{i t}$. Additionally independencies between the processes of the regressors determine the structure of $\Psi_{j}$. In the extreme case of independent processes determining $X_{i t}$ the off-diagonal elements of $\Psi_{j}$ would be zero.

For the elements of the sum of the second expected value in equation (A.5) we write:

$$
E\left(\Delta u_{1-j} \mid \Delta X_{1 i}\right)=d_{j}+\Delta X_{i 1} \varphi_{j}
$$

where $d_{j}$ is a scalar and $\varphi_{j}$ is a $(K \times 1)$ vector. The elements in $d_{j}$ and $\varphi_{j}$ can be derived from the joint distribution of $\left(X_{i 1}, X_{i 0}, X_{i,-1}, \cdots, u_{i 1}, u_{i 0}, u_{i,-1}, \cdots\right)$, (Hsiao, Pesaran, and Tahmiscioglu, 2002)

The projection technique suggested by Hsiao, Pesaran, and Tahmiscioglu (2002) allows $X_{i t}$ to follow trend stationary and first difference stationary data generating processes. Important is however, that the process generating $X_{i t}$ does not follow different trends (stochastic or deterministic) for different $i$. In this case the expected value would not be a function of finite parameters, 
i.e. the incidental parameter problem could not be solved and inconsistent estimates would be the result for finite $T .{ }^{16}$

Inserting the projections into equation (A.5) we get

$$
E\left(\Delta y_{i 1} \mid \Delta X_{i 1}\right)=b^{*}+\sum_{j=0}^{m-1} \gamma^{j}\left[g_{j}+\Delta X_{i 1} \Psi_{j}\right] \beta+\sum_{j=0}^{m-1} \gamma^{j}\left[d_{j}+\Delta X_{i 1} \varphi_{j}\right]
$$

Therefore, we can write for $\Delta y_{i 1}$ the following simplified expression:

$$
\Delta y_{i 1}=\lambda_{0}+\Delta X_{i 1} \lambda_{1}+\xi_{i 1}
$$

where $\lambda_{0}$ and $\lambda_{1}(K \times 1)$ are unknown coefficients. The parameters $\lambda_{0}$ and $\lambda_{1}$ are functions of $b^{*}, \beta, \gamma, g_{j}, \Psi_{j}, d_{j}$ and $\varphi_{j}$. The residual $\xi_{i 1}$ with $E\left(\xi_{i 1} \mid X_{i 1}\right)=0$ is defined as

$$
\xi_{i 1}=\Delta y_{i 1}-E\left(\Delta y_{i 1} \mid \Delta X_{i 1}\right)
$$

The expression for $\xi_{i 1}$ can be obtained from (A.4) and (A.6).

$\xi_{i 1}=\left(\gamma^{m} \Delta y_{i,-m+1}-b^{*}\right)+\sum_{j=0}^{m-1} \gamma^{j}\left\{\Delta X_{i, 1-j}-\left[g_{j}+\Delta X_{i 1} \Psi_{j}\right]\right\} \beta+\sum_{j=0}^{m-1} \gamma^{j}\left\{\Delta u_{i, 1-j}-\left[d_{j}+\Delta X_{i 1} \varphi_{j}\right]\right\}$

Therefore $E\left(\xi_{i 1}^{2}\right)=\sigma_{\xi}^{2}, E\left(\xi_{i 1} \Delta u_{i 2}\right)=-\sigma_{u}^{2}$ and $E\left(\xi_{i 1} \Delta u_{i t}\right)=0$ for $t=3,4, \cdots, T$.

In our empirical application we additionally have to consider two points:

1. The expected value of seasonal dummies and a time trend $E\left(\Delta Z_{1} \mid \Delta Z_{1}, \cdots, \Delta Z_{T}\right)$ is a constant, and is therefore captured by the parameter $\lambda_{0}$.

2. In our empirical model the policy measures, the unemployment and vacancy rate are variables for which we assume that $E\left(h_{i t} p_{i s}\right) \neq 0, E\left(h_{i t} u_{i s}\right) \neq 0$ and $E\left(h_{i t} v_{i s}\right) \neq 0$ for $s \geq t$ and zero otherwise. In this case the variables can be treated as weak exogenous variables if they are included with one lag.

\section{A.2 The likelihood function}

Let $\phi=\left(\lambda_{0}, \lambda_{1}, \gamma, \beta\right)^{\prime}$ and

$$
\Delta Q_{i}=\left(\begin{array}{cccc}
1 & \Delta X_{i 1} & 0 & 0 \\
0 & 0 & \Delta y_{i 1} & \Delta X_{i 2} \\
0 & 0 & \Delta y_{i 2} & \Delta X_{i 3} \\
\vdots & \vdots & \vdots & \vdots \\
0 & 0 & \Delta y_{i T-1} & \Delta X_{i T}
\end{array}\right)
$$

The variance covariance matrix is given by:

\footnotetext{
${ }^{16}$ Notice that in this case the projection would depend on $i$, i.e. $E\left(\Delta X_{i 1-j} \mid \Delta X_{i 1}\right)=g_{i, j}+\Delta X_{i 1} \Psi_{i, j}$
} 


$$
\Omega=\sigma_{u}^{2} \Omega^{*}=\sigma_{u}^{2}\left(\begin{array}{ccccc}
\omega & -1 & 0 & \cdots & 0 \\
-1 & 2 & -1 & \cdots & 0 \\
\vdots & \vdots & \vdots & \vdots & \vdots \\
0 & 0 & 0 & \cdots & 2
\end{array}\right)
$$

where $\omega=\sigma_{\xi}^{2} / \sigma_{u}^{2}$.

Following Hsiao, Pesaran, and Tahmiscioglu (2002) the Likelihood function is then given by:

$$
\ln L=-\frac{N T}{2} \ln (2 \pi)-\frac{N T}{2} \ln \left(\sigma_{u}^{2}\right)-\frac{N}{2} \ln \left|\Omega^{*}\right|-\frac{1}{2} \sum_{i=1}^{N}\left[\left(\Delta y_{i}-\Delta Q_{i} \phi\right)^{\prime} \Omega^{-1}\left(\Delta y_{i}-\Delta Q_{i} \phi\right)\right]
$$

where $\left|\Omega^{*}\right|=1+T(\omega-1)$.

The first order conditions for $\phi, \sigma_{u}^{2}$ and $\omega$ are: ${ }^{17}$

$$
\begin{gathered}
\frac{\partial \ln L}{\partial \phi}=\sum_{i=1}^{N}\left[\Delta Q_{i} \Omega^{-1}\left(\Delta y_{i}-\Delta Q_{i} \phi\right)\right] \\
\frac{\partial \ln L}{\partial \sigma_{u}^{2}}=-\frac{N T}{2 \sigma_{u}^{2}}+\frac{1}{2 \sigma_{u}^{4}} \sum_{i=1}^{N}\left[\left(\Delta y_{i}-\Delta Q_{i} \phi\right)^{\prime}\left(\Omega^{*}\right)^{-1}\left(\Delta y_{i}-\Delta Q_{i} \phi\right)\right] \\
\frac{\partial \ln L}{\partial \omega}=-\frac{N T}{2[1+T(\omega-1)]}+\frac{1}{2 \sigma_{u}^{2}[1+T(\omega-1)]^{2}} \sum_{i=1}^{N}\left[\left(\Delta y_{i}-\Delta Q_{i} \phi\right)^{\prime}\left(v v^{\prime}\right)\left(\Delta y_{i}-\Delta Q_{i} \phi\right)\right]
\end{gathered}
$$

where $v^{\prime}=(T, T-1, \cdots, 2,1) \cdot{ }^{18}$

Setting the first order conditions to zero we obtain:

$$
\begin{gathered}
\hat{\phi}=\left(\sum_{i=1}^{N} \Delta Q_{i} \Omega^{-1} \Delta Q_{i}\right)^{-1}\left(\sum_{i=1}^{N} \Delta Q_{i} \Omega^{-1} \Delta y_{i}\right) \\
\hat{\sigma_{u}^{2}}=\frac{1}{N T} \sum_{i=1}^{N}\left[\left(\Delta y_{i}-\Delta Q_{i} \phi\right)^{\prime}\left(\Omega^{*}\right)^{-1}\left(\Delta y_{i}-\Delta Q_{i} \phi\right)\right] \\
\hat{\omega}=\frac{T-1}{T}+\frac{1}{\sigma_{u}^{2} N T^{2}} \sum_{i=1}^{N}\left[\left(\Delta y_{i}-\Delta Q_{i} \phi\right)^{\prime}\left(v v^{\prime}\right)\left(\Delta y_{i}-\Delta Q_{i} \phi\right)\right]
\end{gathered}
$$

The MLE for $\left(\phi, \sigma_{u}^{2}, \omega\right)$ can be found by maximizing of the log-likelihood function (A.8) by an iterative procedure like Newton-Raphson. Alternatively Hsiao, Pesaran, and Tahmiscioglu (2002) suggest to compute $\hat{\phi}$ and $\hat{\sigma_{u}^{2}}$ for different values of $\hat{\omega}$, and to choose that $\hat{\omega}$ that globally maximises the log-likelihood.

\footnotetext{
${ }^{17}$ The second derivatives can be found in Hsiao, Pesaran, and Tahmiscioglu (2002) pp. 144-145.

${ }^{18}$ See also the definition for $\left(\Omega^{*}\right)^{-1}$ in Hsiao, Pesaran, and Tahmiscioglu (2002).
} 
Hsiao, Pesaran, and Tahmiscioglu (2002) also suggest a simpler, but less efficient estimator for the model (A.1). This so-called minimum-distance estimator (MDE) relies on the quadratic forms in (A.9)-(A.11). In a first step a consistent estimate of $\hat{\omega}$ is obtained by

$$
\hat{\omega}_{\mathrm{mde}}=\frac{T-1}{T}+\frac{1}{\tilde{\sigma}_{u}^{2} N T^{2}} \sum_{i=1}^{N}\left[\left(\Delta y_{i}-\Delta Q_{i} \tilde{\phi}\right)^{\prime}\left(v v^{\prime}\right)\left(\Delta y_{i}-\Delta Q_{i} \tilde{\phi}\right)\right]
$$

where $\tilde{\phi}$ and $\tilde{\sigma}_{u}^{2}$ are estimates that result form a consistent estimator, like the first-differences GMM estimator suggested by Arellano and Bond (1991) that we have used in our empirical analysis. Using $\hat{\omega}_{\text {mde }}$ we obtain the minimum distance estimators for $\phi$ and $\sigma_{u}^{2}$ from (A.9)(A.10). 


\section{References}

Ahn, S., And P. Schmidt (1995): "Efficient Estimation of Models for Dynamic Panel Data," Journal of Econometrics, 68, 5-27.

Arellano, M., and S. Bond (1991): "Some Tests of Specification for Panel Data: Monte Carlo Evidence and an Application to Employment Equations," Review of Economic Studies, $58,277-297$.

Bellmann, L., And R. JaCkman (1996): "Aggregate Impact Analysis," in International Handbook of Labour Market Policy and Evaluation, ed. by G. Schmid, J. O'Reilly, and K. Schömann, pp. 143-162. Edward Elgar.

Blien, U. (2002): "Ein Arbeitsmarktgesamtindikator zur regionalen Mittelverwendung für die aktive Arbeitsmarktpolitik," in IAB-Kompendium Arbeitsmarkt- und Berufsforschung, ed. by G. Kleinhenz. BeitrAB, BD. 250, 335-344.

Blundell, R., and S. Bond (1998): "Initial Conditions and Moment Restrictions in Dynamic Panel Data Models," Journal of Econometrics, 87, 115-143.

Blundell, R., S. Bond, and F. WindmeiJer (2000): "Estimation in Dynamic Panel Data Models: Improving on the Performance of the Standard GMM Estimators," Working Paper 00/12, The Institute for Fiscal Studies.

Boeri, T., And M. Burda (1996): "Active Labor Market Policies, Job Matching and the Czech Miracle," European Economic Review, 40, 805-817.

Bond, S. (2002): "Dynamic Panal Data Models: A Guide to Micro Data Methods and Practice," Working Paper 09/02, The Institute for Fiscal Studies.

Bond, S., And F. WindmeiJer (2002): "Finite Sample Inference for GMM Estimation in Linear Panel Data Models," cemmap working Paper cwp04/02, The Institute for Fiscal Studies.

Calmfors, L. (1994): "Active Labour Market Policy and Unemployment - A Framework for the Analysis of Crucial Design Features," OECD Economic Studies, 22, 7-47.

Calmfors, L., A. Forslund, and M. Hemström (2002): "Does Active Labour Market Policy Work? Lessons From The Swedish Experience," CESifo working Paper no. 675(4), CESifo.

Calmfors, L., and H. Lang (1995): "Macroeconomic Effects of Active Labor Market Programmes in a Union-Wage-Setting Model," Economic Journal, 105 (430), 601-619.

Calmfors, L., and P. Skedinger (1995): "Does Active Labour-Market Policy Increase Employment? Theoretical Considerations and Some Empirical Evidence from Sweden," Oxford Review of Economic Policy, 11 (1), 91-109.

Franz, W., and W. Smolny (1994): "The Measurement and Interpretation of Vacancy Data and the Dynamics of the Beveridge Curve: The German Case," in Measurement and Analysis of Job Vacancies, ed. by J. Muysken. Aldershot.

Hagen, T. (2003): "Three Approaches to the Evaluation of Active Labour Market Policy in East Germany using Regional Data," ZEW Discussion Paper No. 03-27, ZEW.

Heckman, J., R. LaLonde, and J. Smith (1999): "The Economics and Econometrics of Active Labor Market Programs," in Handbook of Labor Economics Vol.III, ed. by O. Ashenfelter, and D. Card, pp. 1865-2097. Elsevier, Amsterdam.

Holmlund, B., And J. Linden (1993): "Job Matching, Temporary Public Employment and Equilibrium Unemployment," Journal of Public Economics, 51, 329-343. 
Hsiao, C., M. Pesaran, and A. Tahmiscioglu (2002): "Maximum likelihood Estimation of Fixed Effects Dynamic Panel Data Models covering short time periods," Journal of Econometrics, 109, 107-150.

Hujer, R., U. Blien, M. Caliendo, and C. Zeiss (2002): "Macroeconometric Evaluation of Active Labour Market Policies in Germany - A Dynamic Panel Approach Using Regional Data," Discussion Paper No. 616, IZA.

Hujer, R., M. Caliendo, and S. Thomsen (2003): "New Evidence on the Effects of Job Creation Schemes in Germany - A Matching Approach with Threefold Heterogeneity," Working Paper, J.W.Goethe-University, Frankfurt.

Layard, R., S. Nickell, and R. Jackman (1991): Unemployment - Macroeconomic Performance and the Labour Market. Oxford University Press, New York.

Lehmann, H. (1995): "Active Labour Market Policies in the OECD and in Selected Transition Economies," Working paper No. 539-96, World Bank Policy Reasearch.

OECD (1993): Employment Outlook. Paris.

Petrongolo, B., and C. Pissarides (2001): "Looking into the Black Box: A Survey of the Matching Function," Journal of Economic Literature, XXXIX (June), 309-431.

Pissarides, C. (2000): Equilibrium Unemployment Theory. MIT Press.

Puhani, P. (1999): Evaluating Active Labour Market Policies - Empirical Evidence for Poland During Transition.ZEW Economic Studies, Vol.5. Physica-Verlag, Heidelberg, New York.

WindmeiJer, F. (2000): "A Finite Sample Correction for the Variance of Linear Two-Step Estimators," Working Paper 00/19, The Institute for Fiscal Studies. 


\section{IZA Discussion Papers}

\begin{tabular}{|c|c|c|c|c|}
\hline No. & Author(s) & Title & Area & Date \\
\hline 901 & $\begin{array}{l}\text { P. F. Orazem } \\
\text { M. Vodopivec }\end{array}$ & $\begin{array}{l}\text { Do Market Pressures Induce Economic } \\
\text { Efficiency: The Case of Slovenian } \\
\text { Manufacturing, 1994-2001 }\end{array}$ & 4 & $10 / 03$ \\
\hline 902 & $\begin{array}{l}\text { P. Frijters } \\
\text { M. A. Shields } \\
\text { S. Wheatley Price }\end{array}$ & $\begin{array}{l}\text { Immigrant Job Search in the UK: Evidence from } \\
\text { Panel Data }\end{array}$ & 1 & $10 / 03$ \\
\hline 903 & $\begin{array}{l}\text { S. Girma } \\
\text { H. Görg }\end{array}$ & $\begin{array}{l}\text { Evaluating the Causal Effects of Foreign } \\
\text { Acquisition on Domestic Skilled and Unskilled } \\
\text { Wages }\end{array}$ & 2 & $10 / 03$ \\
\hline 904 & $\begin{array}{l}\text { S. P. Jenkins } \\
\text { P. Van Kerm }\end{array}$ & $\begin{array}{l}\text { Trends in Income Inequality, Pro-Poor Income } \\
\text { Growth and Income Mobility }\end{array}$ & 1 & $10 / 03$ \\
\hline 905 & $\begin{array}{l}\text { D. Weichselbaumer } \\
\text { R. Winter-Ebmer }\end{array}$ & $\begin{array}{l}\text { Rhetoric in Economic Research: The Case of } \\
\text { Gender Wage Differentials }\end{array}$ & 7 & 10/03 \\
\hline 906 & $\begin{array}{l}\text { D. Weichselbaumer } \\
\text { R. Winter-Ebmer }\end{array}$ & $\begin{array}{l}\text { A Meta-Analysis of the International Gender } \\
\text { Wage Gap }\end{array}$ & 7 & $10 / 03$ \\
\hline 907 & $\begin{array}{l}\text { A. Dupuy } \\
\text { L. Borghans }\end{array}$ & $\begin{array}{l}\text { Supply and Demand, Allocation and Wage } \\
\text { Inequality: An International Comparison }\end{array}$ & 1 & $10 / 03$ \\
\hline 908 & M. Leonardi & Product Demand Shifts and Wage Inequality & 1 & $10 / 03$ \\
\hline 909 & M. Leonardi & $\begin{array}{l}\text { Firm Heterogeneity in Capital/Labor Ratios and } \\
\text { Wage Inequality }\end{array}$ & 1 & $10 / 03$ \\
\hline 910 & $\begin{array}{l}\text { P. Díaz-Vázquez } \\
\text { D. Snower }\end{array}$ & $\begin{array}{l}\text { On-the-Job Training, Firing Costs and } \\
\text { Employment }\end{array}$ & 5 & $10 / 03$ \\
\hline 911 & J. Wagner & $\begin{array}{l}\text { Are Nascent Entrepreneurs Jacks-of-all-Trades? } \\
\text { A Test of Lazear's Theory of Entrepreneurship } \\
\text { with German Data }\end{array}$ & 5 & $10 / 03$ \\
\hline 912 & $\begin{array}{l}\text { D. Checchi } \\
\text { A. Filippin }\end{array}$ & An Experimental Study of the POUM Hypothesis & 1 & $10 / 03$ \\
\hline 913 & $\begin{array}{l}\text { S. Pivnenko } \\
\text { D. DeVoretz }\end{array}$ & $\begin{array}{l}\text { The Recent Economic Performance of Ukrainian } \\
\text { Immigrants in Canada and the U.S. }\end{array}$ & 1 & $10 / 03$ \\
\hline 914 & $\begin{array}{l}\text { A. R. Cardoso } \\
\text { P. Portugal }\end{array}$ & $\begin{array}{l}\text { Bargained Wages, Wage Drift and the Design of } \\
\text { the Wage Setting System }\end{array}$ & 5 & $10 / 03$ \\
\hline 915 & $\begin{array}{l}\text { R. Hujer } \\
\text { C. Zeiss }\end{array}$ & $\begin{array}{l}\text { Macroeconomic Impacts of ALMP on the } \\
\text { Matching Process in West Germany }\end{array}$ & 6 & $10 / 03$ \\
\hline
\end{tabular}

An updated list of IZA Discussion Papers is available on the center's homepage www.iza.org. 